\title{
Why refugee visa credibility assessments lack credibility: A
}

\section{Critical Discourse Analysis}

\author{
Laura Smith-Khan*
}

\begin{abstract}
Whether those seeking asylum can be believed is a central concern in both public discourse and institutional processes. As a result, credibility assessments have become an important component of the latter. This article contributes to existing scholarship on credibility assessments by critically examining the discourse and related 'language ideologies' underlying them. The examination includes published tribunal decisions on appeals of institutional rejections of asylum-seeker applications, and the tribunal's official credibility assessment guidelines. It considers how constructions of language and diversity affect the way credibility is assessed in visa decision-making. In the application process, sole authorship of the texts produced is discursively assigned to the asylum-seekers. This discourse is problematic as it constructs credibility as attaching to them alone. However, this contradicts the sociolinguistic realities: the texts produced in this setting are institutionally controlled and result from the interaction of multiple participants. The examination also demonstrates how the essentialisation of culture and linguistic diversity can create implausibility. Institutional discourse thus creates serious challenges for applicants, who must communicate 'credibly' to gain protection, even though this communication and its evaluation are far from wholly within their control.
\end{abstract}

*Chancellor's Postdoctoral Research Fellow, University of Technology Sydney.

Laura.Smith-Khan@uts.edu.au

This is the pre-publication, accepted version of the paper. The published version is available at https://doi.org/10.1080/10383441.2019.1748804 


\section{Keywords}

Australia, asylum, credibility, discourse, interpreting, language, refugee,

\section{Introduction}

The trustworthiness of those seeking asylum is a question of central interest in refugee status determination (RSD), with credibility assessments an increasingly common component of these processes. RSD is undoubtedly a challenging exercise, with many asylum-seekers having little more than their story and feelings to share with the government officials tasked with assessing their claims and thus determining whether each asylum-seeker has a well-founded fear of persecution, as required to meet the refugee definition under international law. ${ }^{1}$ However, the increasing centrality of such assessments is said to be linked to a rising culture of disbelief, both within government institutions and in the broader public discourse on refugees more generally ${ }^{2}$ and aligns with an increasing emphasis in immigration policy on the securitization of national borders. ${ }^{3}$

The prevalence of such assessments means that the way institutions and their agents conceptualise credibility is of crucial importance. The credibility assessments they employ have therefore started attracting scrutiny across multiple research disciplines. This article offers a novel contribution to existing work by applying sociolinguistic scholarship to examine the way official institutional texts frame credibility and by identifying and problematizing the 'language ideologies' underlying these, centring on Australian texts and appeals. Recent Australian policy responses to asylum-seekers have faced much criticism globally, and also have been found to share commonalties with and even influence policy-making in other

\footnotetext{
${ }^{1}$ See discussion in Luker (2013). The refugee definition is set out in art $1 \mathrm{~A}(2)$ of the UN Convention relating to the Status of Refugees (adopted 28 July 1951, entered into force 22 April 1954) 189 UNTS 137.

${ }^{2}$ Every and Augoustinos (2008); Kagan (2003); Smith-Khan (2019b); Sweeney (2009).

${ }^{3}$ Fox O’Mahony and Sweeney (2010).
} 
asylum-seeker-receiving countries of the global north. ${ }^{4}$ This paper focuses on the merits review stage of Australian asylum decision-making. This is arguably the most crucial stage, given the very limited options for further review. It draws on publicly available texts, a necessity given that researchers have very limited opportunities to access data in this area, often seemingly the result of concerted efforts by government authorities. ${ }^{5}$

In what follows, the issue of credibility in refugee decision-making procedures is introduced, with a summary of the common indicators involved, highlighting the major criticisms that they have attracted. Next, the study is introduced, with an explanation of the key research questions, and a description of the data and theoretical approach used to explore them. The subsequent sections present key findings from the analysis of this data. They explore how the institutional texts - credibility assessment guidelines and a set of published 'merits review' appeals decisions - discursively represent the main social actors involved in refugee applications and appeals. Of particular interest is how the discourse conceptualises the roles these actors play in the communication that takes place in this setting, understandings of linguistic and cultural diversity and how these should be accommodated. The analysis draws on examples from four decisions to demonstrate how these understandings of communication and diversity and the recommendations they produce are applied in practice. The examination compares the individual decision-makers' approaches with the official guidance and reveals some of the challenges for applicants in their quest to maintain or regain credibility. The representations drawn out of the Guidelines and decisions are then explicitly linked to some of the problematic language ideologies they rely on. The article finds cause for a revised understanding of communication and text creation, and of diversity, throughout these

\footnotetext{
${ }^{4}$ Ghezelbash (2018). See also literature on common credibility indicators below, focused on a number of countries across Western Europe, the US, the UK, New Zealand and Canada.

${ }^{5}$ See a discussion of this challenge in Nikolaidou, Rehnberg and Wadensjö (2019).
} 
processes. It thus offers a novel, ideology-level challenge to the widespread use of credibility assessments in their current form and concludes with suggestions of possible next steps.

\section{Credibility in Refugee Decision-making Procedures}

A broad range of research across multiple disciplines has explored the use of credibility assessments in refugee decision-making and identifies a common set of indicators used to test credibility. Internal consistency is expected, that is, consistency across different institutional texts such as visa application forms, written statements or statutory declarations, and entry and RSD interviews. External consistency evaluates the refugee narrative, created through these texts, against officially endorsed country information and other sources of information decision-makers may seek out. Evaluations of plausibility, coherence and level of detail consider whether or not particular events or explanations appear likely and whether the narrative and particular elements therein are produced in sufficient detail. Finally, considerations related to demeanour involve evaluating whether non-verbal communication, including for example body language and eye contact, give the appearance of honesty.

Perhaps unsurprisingly, these indicators have attracted a range of criticisms. For example, reliance on internal consistency is criticised in psychology-based studies. These argue that it is normal for recall to vary and for stories to be retold differently across time, with the effects of trauma and cultural differences adding extra explanations for apparent inconsistencies. ${ }^{6}$ Other research has highlighted the influence that procedural and legal structures have on the way in which asylum-seekers communicate and how they have to shape their complex and individual lived experiences to fit an institutionally expected refugee identity. ${ }^{7}$ This process, in which the refugee narrative is transformed to meet institutional requirements, is then repeated again in the drafting of the official record of the decision. Such processes are understood as

\footnotetext{
${ }^{6}$ Nolan and Goodman-Delahunty (2015); Hunter et al (2013) Evans Cameron (2008).

${ }^{7}$ Blommaert (2001); Vogl (2013); Zagor (2014).
} 
'entextualization' in linguistics, involving a reformulation of the narrative to conform to the required bureaucratic genre. ${ }^{8}$ Far from being solitary activities, these entextualization processes require the interactions and contributions of other actors, including decision-makers, and often interpreters and lawyers. ${ }^{9}$

External consistency is particularly problematic for individuals whose lived experiences clash with institutionally preferred sources of knowledge. Official country information may present harmful contradictions for people who are minorities within their home country, or whose experiences are less visible as they relate to private rather than public life, as demonstrated in a range of research on sexuality and gender based asylum claims. ${ }^{10}$ For such people, this official country information which, ironically, may be produced by the very authorities from whom they fear persecution, may act to re-stigmatise them. Effectively, this means that asylum agencies may take the word of the alleged persecutors over that of the asylum-seeker. ${ }^{11}$ Further, official country reports may sometimes be influenced by geopolitical or professional motivations to paint a certain picture of a country that is inadvertently detrimental to the asylum-seeker. ${ }^{12}$ For example, where a country has received substantial foreign funding for their security forces, their security agencies may tend to present overly positive accounts of security improvements and minimise any ongoing issues.

Plausibility, coherence and level of detail are liable to be impacted by all these factors. Further, they rely heavily on individual decision-makers' perception or expectations, which are liable to differ from person to person in often under-acknowledged ways. ${ }^{13}$ Further, an under-

\footnotetext{
${ }^{8}$ For a detailed explanation and discussion of 'extextualization', see for example: Jacquemet (2009); Maryns (2005b).

${ }^{9}$ Smith-Khan (2017b); Kjelsvik (2014); Eastmond (2007).

${ }^{10}$ Millbank (2009); Shuman and Bohmer (2014); McKinnon (2009).

${ }^{11}$ Shuman and Bohmer (2012); Bohmer and Shuman (2007a).

12 For a more detailed and comprehensive analysis of the project's research interview data, which included qualitative interviews with Australian migration practitioners, see Smith-Khan (2019c).

${ }^{13}$ Tipton (2008); Noll (2005); Spotti (2019).
} 
appreciation of the effects of communicating in a second language ${ }^{14}$ and of interpreting on the level of detail present in the final record may contribute significantly to a perceived lack of detail. $^{15}$

Finally, reliance on demeanour has attracted heavy criticism due to its cultural relativity and more general unreliability even where cultural diversity is not a factor. ${ }^{16}$ This has resulted in the incorporation of some cautions or limits on how it should be used, including in the Australian context where decision-makers are advised to 'exercise care' when relying on demeanour as the reason for a negative credibility finding, and to 'be aware of the effect of cultural differences on demeanour and oral communication'. ${ }^{17}$ Previous research in Australia has found that demeanour is very rarely explicitly given as a reason for an adverse credibility decision, but suggests that it may influence credibility assessments in 'unacknowledged ways', ${ }^{18}$ such as framing the applicant's responses as 'vague, lacking in detail, inconsistent or tentative' ${ }^{19}$

Individuals who arrive in Australia with a valid passport and visa have the right to apply for a permanent 'protection visa' ${ }^{20}$ At the first instance, they make an application either in paper or online, involving completing mandated forms, paying a nominal fee and later, attending an interview at the Department of Home Affairs. ${ }^{21}$ If their application is unsuccessful at this stage,

\footnotetext{
${ }^{14}$ In some contexts, not only the asylum-seeker but also the decision-maker and/or the interpreter may use a second language as a lingua franca in interviews, such as in some of the interviews included in Maryns' study of the Belgian asylum procedures. See Maryns (2005b).

${ }^{15}$ Maryns (2005a), (2005b).

${ }^{16}$ Nolan and Goodman-Delahunty (2015).

${ }^{17}$ Administrative Appeals Tribunal, Migration and Refugee Division (2015), Guidelines on the Assessment of Credibility, para 34. Available at

<https://www.aat.gov.au/AAT/media/AAT/Files/MRD\%20documents/Legislation\%20Policies\%20Guidelines/ Guidelines-on-Assessment-of-Credibility.pdf> ('Guidelines').

${ }^{18}$ Coffey (2003) p 387.

${ }^{19}$ Coffey (2003) p 386.

${ }^{20}$ Migration Act 1958 (Cth) s 36. Those who arrive without a valid visa are unable to apply for permanent protection and have more restricted visa application options and access to merits and/or judicial review. Guidance and decision-making for this group are less available for public scrutiny. For more information about policies for unauthorised arrivals, see for example Chia et al (2014); McDonald and O'Sullivan (2018).

${ }^{21}$ I will refer to it as the 'Immigration Department', as the name of the department responsible changes frequently. The main form required at the time of application is Form 866, which is 33 pages long and contains 87 questions/sections. A copy - current in August 2019 - can be accessed online at
} 
they may seek merits review at the Administrative Appeals Tribunal (AAT). ${ }^{22}$ At the AAT stage, the review involves reconsidering the merits of their case, as at the present time. In any situation where the decision-maker, known as a Tribunal Member, is unable to reach a positive decision on the papers, they must invite the applicant to attend a 'hearing' to explore their claim in more detail, present any adverse information to them and give them a chance to respond to this before reaching a negative decision. ${ }^{23}$ This process is understood to be 'quasi-inquisitorial', with the Tribunal Member having 'almost complete control $\ldots$ in the conduct of hearings' ${ }^{24}$ While applicants have the right to an interpreter, there is no right to be represented, and in some cases, the tribunal member chooses whether or not a legal representative can be present and whether, when and how much they are allowed to speak. ${ }^{25}$ Refugee review hearings at the AAT are closed to the public, but the AAT publishes a selection of anonymised decisions online. The key document officially setting out the guidelines for merits review assessment of credibility are available in a 2015 document entitled the Guidelines on the Assessment of Credibility. ${ }^{26}$ This is a near-verbatim reproduction of an earlier document created by the nowdefunct Refugee Review Tribunal (RRT), with the newer document differing only in its naming of the newer body. ${ }^{27}$

The merits review stage is very important: if applicants are unsuccessful at this point, they have very limited scope for judicial review, especially for credibility-based decisions, which are often considered questions of fact and therefore generally not open to judicial scrutiny. ${ }^{28}$

https://web.archive.org/web/20190819005055/https://immi.homeaffairs.gov.au/form-listing/forms/866.pdf. As of August 2019, the application fee for an onshore protection visa was AU $\$ 40$.

${ }^{22}$ These reviews were formerly conducted by a separate Refugee Review Tribunal, but were transferred into the existing responsibilities of the AAT in 2015.

${ }^{23}$ Migration Act 1958 (Cth) s 425.

${ }^{24}$ Crock and Berg (2011).

${ }^{25}$ Migration Act 1958 (Cth) s 366A. Although see Crock and Berg (2011), pp 591-2 for a discussion of some of the limitations to this.

${ }^{26}$ I will refer to them as the 'Guidelines'. See n 16.

${ }^{27}$ See $\mathrm{n} 20$.

${ }^{28}$ Crock and Berg (2011) discuss the increasingly restrictive scope for judicial review of migration decisions in Australia. For a discussion on the distinction between questions of fact and law in this area, see Vedsted-Hansen, (2005). 
While processing times for the first-instance and review stage vary on a case-by-case basis, waiting times between each step (lodging applications/appeals, being invited for an interview/hearing and receiving a decision) have been reported as ranging from several months to years. This creates concerns in terms of asylum-seekers' mental health, rapport and trust with their representatives, and their ability to present consistent narratives and remember apparently trivial details. ${ }^{29}$

\section{Studying Credibility in Institutional Texts}

To better contextualise the credibility indicators on which credibility assessments are based, the current study sought to examine the way institutional discourse presents credibility and the processes in place for assessing it. The analysis centred on three key questions. First, it asked how participants are discursively represented in official texts. Second, it aimed to uncover the 'language ideologies' underlying these representations. ${ }^{30}$ Third, it considered the implications these discursive representations and ideologies have for the (re)construction of refugee credibility in visa decision-making processes.

The study drew on a range of data, including the Guidelines mentioned above, which are 51 paragraphs (11 pages) in length. 27 published protection visa review decisions from the AAT and RRT were also collected. The sample was determined by using a key term word search of 'credib*' on the AUSTLII online database, with the results sorted by relevance and selecting the top ten results from the AAT and top 20 from the RRT, given responsibility for reviewing refugee visa applications was only recently transferred to the AAT. Three decisions from the RRT were removed because they pre-dated the creation of the Guidelines. The sample was thus purposive, seeking to explore appeals in which credibility was explicitly considered in reaching a decision. Incidentally, while it was not a random sample and no claims are made about its

\footnotetext{
${ }^{29}$ Smith-Khan (2019c).

${ }^{30}$ See eg Eades (2012). This term is explained in more detail below.
} 
representativeness across all decisions, the percentage of successful appeals in the group of decisions in the study (11 percent, or 3 of 27) is similar to overall success rates in recent years. For example, in 2017-2018 and 2016-2017 respectively, the AAT remitted (sent back to the Immigration Department with an instruction that the person met the refugee definition) 10 and 15 percent of appeals in which a substantive decision could be made. ${ }^{31}$

Early analysis of this data formed the basis of a preliminary article, focusing solely on the representation of social actors. ${ }^{32}$ Two of the published decisions then formed the basis of case studies in a subsequent article, which explored in greater depth the representation and accommodation of diversity in the Guidelines, and its impact in these two decisions. ${ }^{33}$ These two decisions are included below as they provide rich examples of how cultural, linguistic and other arguments are presented to address credibility concerns, and the reception they received, and add significant weight to the arguments then presented about the language ideologies underlying these processes. They are contrasted with two successful reviews to demonstrate diversity in decision-making, and the scope for very different outcomes.

Data analysis was further informed and supplemented by progressively conducting a set of semi-structured qualitative interviews with eight registered migration agents ${ }^{34}$ throughout the course of the project, exploring their experiences dealing with refugee credibility in applications and appeals. While a detailed examination of the research interview data is

\footnotetext{
${ }^{31}$ This percentage includes 73 percent of originally lodged review applications. The remaining 27 percent were either 'withdrawn, did not meet application requirements or were dismissed by the Tribunal on the basis that the applicant failed to appear' (AAT, Аnnual Report 2016-17, https://www.aat.gov.au/AnnualReports/201617/part3.html\#3.

${ }^{32}$ Smith-Khan (2017c).

${ }^{33}$ Smith-Khan (2017a). These, and another case study, focused on media and public discourse on refugee credibility, constituted the substantive sections of doctoral thesis completed in Smith-Khan (2018).

${ }^{34}$ In Australia, there are multiple avenues to become a Registered Migration Agent (RMA). For non-lawyers, this includes completing a Graduate Diploma in Migration Law and Practice and applying to the Office of Migration Agents Registration Authority. Practicing lawyers may apply directly for registration, without completing any additional training beyond that which is required for admission to the legal profession. Individuals must be RMAs in order to assist visa applicants at the level of the Department of Home Affairs and/or the AAT. The current study included seven lawyer RMAs and one non-lawyer RMA.
} 
presented elsewhere,${ }^{35}$ the issues raised and explored below were both informed by and helped to inform those interviews. While ideally, direct observation of hearings would have provided additional valuable insight into the actual practices and experiences of the various actors involved in these procedures, this type of access is rarely granted in the Australian context, ${ }^{36}$ and past attempts by the researcher to gain the cooperation of the Immigration Department and RRT have been unsuccessful. ${ }^{37}$ While the need for confidentiality in appeals dealing with sensitive personal content is understandable, the effect is that published official written reasons are the only version of events publicly available. This makes it all the more crucial to closely scrutinize their creation and content.

In analysing this data, the project was interested in uncovering dominant discourses. This was based on the understanding that "different actors "see" and represent social life in different ways ${ }^{38}$ and that powerful groups mobilise their chosen discourses to justify the status quo, entrench their power and maintain inequality and control, usually to the disadvantage and detriment of minorities. ${ }^{39}$ Therefore, this study adopts a Critical Discourse Analysis approach, which seeks to uncover and denaturalise these dominant discourses in an attempt to improve outcomes and decrease inequality for those members of society they unfairly disadvantage. More specifically, the study adopts a Social Actor Analysis approach, ${ }^{40}$ which focuses on examining sociosemantic choices made in dominant discourses (in the current study, within the Guidelines and published decisions), specifically, how they assign certain roles and agency to various social actors. ${ }^{41}$ Building on the foundational analyses published in 2017 , the current

\footnotetext{
${ }^{35}$ Smith-Khan (2019c).

${ }^{36}$ Luker (2013) and Vogl (2013) are two notable exceptions,

${ }^{37}$ See Smith-Khan (2017b); (2018) pp 17-18.

${ }^{38}$ Fairclough (2001), p 123.

${ }^{39}$ van Dijk (2008).

40 van Leeuwen (1996), (2008).

${ }^{41}$ van Leeuwen (2008), p 23, explains that this approach involves first considering the 'sociological and critical relevance' of categorisation, before turning to consider how these categories are 'realized linguistically'.
} 
article extends its focus to explicitly identify and critically explore the 'language ideologies' that underlie these discourses.

A term coined by linguistic anthropologists and now common in sociolinguistics, language ideologies are 'the taken-for-granted assumptions about how language works' ${ }^{42}$ The reason for critically examining them is that these assumptions can have serious effects. They may 'play an important role in the reproduction of inequality' by rationalising existing conduct and processes. ${ }^{43}$ This aligns with a Gramscian understanding of how language can be used to reinforce hegemony: 'dominant groups can solidify their hold on elite positions within society by using their language to exclude'. ${ }^{44}$ Therefore, by examining the roles the discourse assigns to the various actors involved in the RSD and credibility assessment process, and interrogating the beliefs about language and culture connected with this role allocation, the article aims to uncover and problematize the language ideologies which justify the current system of assessing credibility. The key findings of this examination are set out below, first exploring the way the social actors involved in RSD are presented in the institutional discourse, and then linking these representations with key language ideologies. These language ideologies are critically examined, leading to a concluding discussion that explores the implications of this analysis for credibility assessments in Australian review decisions and beyond.

\section{The Representation of Social Actors}

\section{AAT Guidelines}

An examination of the Guidelines identifies clear divisions in the roles assigned to the various actors involved in the visa application process. On one level, this may seem unsurprising given the very different reasons for which these actors appear in this context. However, this division of roles - both within the text of the Guidelines but also in the design of the procedures

\footnotetext{
42 Eades (2012), p 474.

${ }^{43}$ Eades (2012), p 474

${ }^{44}$ Ives (2009), p 672. See also Smith-Khan (2018), pp 140-141.
} 
themselves - reflects a dominant discourse that divides responsibility for text creation unequally across the different participants, in ways that have important implications for credibility.

\section{The applicant: text creator and group member}

Asylum-seekers are presented as 'applicants'. This is logical, given that the Guidelines are open for use across all migration decisions, rather than those involving protection visas only. However, the effect of this choice is that it presents asylum-seekers according to their primary institutional function, as individuals applying for a visa, with the broader international human right to protection backgrounded. Further, by presenting them as 'applying', the text emphasises their status as potential refugees only: their merit for a visa (and their credibility) must be determined, rather than accepted as fact.

These applicants are presented as subjective beings, whose behaviour and thoughts cannot be divorced from their 'social or cultural background'. Their subjectivity is highlighted in 17 of the 51 paragraphs in the Guidelines, which instruct, for example, on the need to deal with sensitive matters in a 'culturally sensitive way' 45 and warning on the 'effect of cultural differences on demeanour and oral communication'. ${ }^{46}$ These types of cautions which underline cultural difference, draw attention to the tribunal hearing as a site of intercultural communication. Yet, there is little to no reference to a factor arguably more relevant in communication: linguistic diversity. Further, they tend to essentialise the applicant's subjectivity, and limit their focus to conduct within the hearing. As will become clear below, they also form a striking contrast to the way the decision-maker is presented.

Finally, and importantly, the Guidelines present the asylum-seeker as primary (if not sole) creator of the refugee narrative (and all the various texts constituting it). This is demonstrated

\footnotetext{
${ }^{45}$ Guidelines, para 24.

${ }^{46}$ Guidelines, para 34.
} 
through the prevalence of constructions in which the applicant is presented as possessing 'claims', 'evidence' and 'accounts' and also in the types of structures in which the applicant is assigned an agentive role (ie they are the subject): mainly in those where the action involves 'presenting the case', 'providing or giving evidence' and similar. This role as primary communicator is even clearer when contrasted with the roles assigned to the other participants.

\section{The reasonable decision-maker: institutional insider and receiver of information}

In contrast to applicants, decision-makers are most commonly referred to as 'the tribunal' (in 75 instances) or otherwise as 'members' (of the tribunal). In this way they are 'spacialized', literally taking on the identity of the institution in which they conduct their work. ${ }^{47}$ Further, use of the term 'member' emphasises their institutional affiliation, reinforcing their status as legitimate insiders. Their spacialization resembles broader legal linguistic conventions, for example referring to a judge or judges as 'the Court'. These conventions effectively closely connect the decision-maker with the institution. In combination with subsequent references to 'it' (rather than they, he or she), these constructions suggest the possibility of uniformity, consistency and neutrality between the different individuals playing this role. ${ }^{48}$

Unlike the applicant, decision-makers' subjectivity is idiosyncratic rather than linked to their membership of a particular group, and they are assumed to be able to overcome it, in the one time it is explicitly mentioned in the Guidelines:

Findings made by the tribunal on credibility should be based on relevant and material facts.

What is capable of being believed is not to be determined according to the Member's

\footnotetext{
47 This can include both actual physical spaces, but also institutionally conceptualised spaces that may not be strictly tied to one geographic location: van Leeuwen (1996), p 59.

${ }^{48}$ For a discussion on 'the court', see Tiersma (1999). This tendency extends beyond legal contexts. For example, see discussion in Verschueren (2012), pp 84-6, on the tendency in Western English-language scholarly writing to favour constructions that background the author, such as passive or third-person constructions, as a means of negating their subjectivity.
} 
subjective belief or gut feeling about whether an applicant is telling the truth or not. A Member should focus on what is objectively or reasonably believable in the circumstances. ${ }^{49}$

They are also instructed to 'maintain, and be seen to have, an open mind'. ${ }^{50}$ These instructions assume that decision-makers, unlike asylum-seekers, are capable of separating themselves from the influences of their cultural and social backgrounds (which are not explicitly acknowledged in the text at all), to achieve objectivity or reasonableness. Moreover, they demonstrate a preference for decision-makers' expertise regarding the applicant's background, assigning them the role of deciding whether a certain act or explanation is reasonable in the given circumstances. This creates a hierarchy to diversity, wherein decisionmakers have the privilege of individual idiosyncrasies which they are expected to be capable of overcoming to achieve objectivity. In contrast, applicants are culturally and socially different from the assumed 'normal' of decision-makers' ways of being and understanding the world, based on their membership of particular social groups whose members behave in particular (stereo)typical ways. The applicants' divergence from this normal is something they cannot overcome - they cannot divorce themselves from their background or group membership - and because it may taint their explanations or conduct, decision-makers are advised to manage or accommodate it.

Finally, unlike the asylum seekers's role as primary communicator, the overwhelming majority of the actions assigned to decision-makers relate to cognitive processes - receiving and testing texts, rather than participating in their creation. These actions fall into three key groups - those related to the deciding process, such as considering, assessing and having regard to (35 mentions), those related to reaching conclusions, like finding, believing and being satisfied (36 mentions), and those related to expectations, for example, being aware of certain

\footnotetext{
${ }^{49}$ Guidelines, para 9, emphasis added.

${ }^{50}$ Guidelines, para 18.
} 
factors and exercising care (18 mentions). While these are undoubtedly important functions of decision-makers, the overwhelming focus on this element of their role almost completely erases the many ways in which they act as co-creators of the texts produced. This includes a number of sociolinguistic functions which all have the potential to seriously impact refugee credibility, such as their control over the hearing process as a whole, including who can participate and how, and their roles in questioning and in reformulating communication into a final written decision record.

\section{Others}

Some other participants are also mentioned in the Guidelines, albeit much less frequently. For example there is only one mention of 'representatives' as actors - and they are mentioned simply as potential users of the Guidelines. ${ }^{51}$ One other indirect mention is access to 'advice' (which presumably they provide), noting that care should be taken where this is lacking. ${ }^{52}$ This largely backgrounds the valuable and complex contributions that legal representatives make to applications and appeals, and more specifically the way they shape how claims or responses to adverse information are communicated. ${ }^{53}$

Interpreters and interpreting garner three mentions. For example, decision-makers are instructed to take care when evidence is provided 'through an interpreter' 54 and the gender of the interpreter should be considered when sensitive evidence is given. ${ }^{55}$ These demonstrate some recognition of the interpreter's status as a social actor, but the term 'through' suggests that the interpreter acts as a simple conduit and backgrounds the plethora of linguistic choices interpreters make and the impact these have on text production. ${ }^{56}$

\footnotetext{
${ }^{51}$ Guidelines, para 51.

52 Guidelines, para 12.

${ }^{53}$ See examples of these contributions in Smith-Khan (2017b, 2019c); Hambly (2019); Bohmer and Shuman (2007b).

${ }^{54}$ Guidelines, para 21.

${ }^{55}$ Guidelines, para 24.

56 The complexity and inevitability of these choices are demonstrated in several studies. See for example Susanne van der Kleij (2015); Tipton (2008).
} 
Finally 'other persons' and 'witnesses' are mentioned. Expert witnesses are assigned value conditionally, based on being 'appropriately qualified', ${ }^{57}$ with an expectation, like decisionmakers, that they should be capable of giving 'objective, unbiased opinion' 58 'Other persons' could also include lay witnesses. These are framed in similar ways to applicants, and in some cases the Guidelines combine the two groups, describing how these 'persons' 'give' evidence and may vary in their 'ability to recall an event' and in their 'emphasis and perspective' of events. ${ }^{59}$ Therefore, like applicants, their role as evidence-givers largely presents them as communicating in isolation.

\section{Published Decisions}

The published decisions provide a point of comparison to the representations in the Guidelines. In these, the handling of the applicant is best understood by first examining the way the decisions present the decision-makers and other participants.

\section{Decision-makers}

Thirteen of the 18 decision-makers ${ }^{60}$ included in the collection of decisions included in the study refer to themselves as 'the Tribunal' and 'it', three refer to themselves consistently by singular personal pronoun 'I', and two more mix these two. Each decision-maker is consistent in this usage across their decisions (where multiple decisions are included in the study).

The decision-makers often refer to themselves in active constructions (ie 'I' + verb), but mostly do this when describing actions that are cognitive processes, in line with the roles the Guidelines emphasise. Some also include some descriptions of their questioning and confronting roles, for example reporting 'the Tribunal asked', ${ }^{61}$ or 'I put to the applicant'. ${ }^{62}$ Even those decision-makers who background their questioning role still foreground cognitive

\footnotetext{
${ }^{57}$ Guidelines, para 39.

${ }^{58}$ Guidelines, para 40.

${ }^{59}$ Guidelines, paras 22, 30.

${ }^{60}$ A full list of the decisions, including decision-maker names, appears at the end of this article.

${ }^{61}$ For example, 1210413 [2013] RRTA 172 (18 February 2013) at 67.

${ }^{62}$ Eg. 1319789 (Refugee) [2015] AATA 3453 (25 September 2015) at several places.
} 
processes, with constructions including 'I do not accept' ${ }^{\prime 3}$ and 'the Tribunal is not satisfied'. ${ }^{64}$ Overall, this demonstrates a prioritization or focus on cognitive functions over the decisionmakers' role as communicators, or text co-constructors, reflecting the way they are represented in the Guidelines, and therefore a shared understanding of the decision-maker's role(s) across the Guidance and decisions. However, at the same time, the diversity of approaches the different decision-makers adopt in their writing provides evidence of the scope for variety, challenging the expectation of one standard, uniform process.

\section{Others}

Other participants are mentioned infrequently in the decisions, just as they garner little mention in the Guidelines. In four cases it is not even clear whether an interpreter was used or not. ${ }^{65}$ Out of the 20 reviews where it is clear an interpreter was present, eleven only include a generic pro-forma reference, for example, 'the Tribunal hearing was conducted with the assistance of an interpreter in the Sinhala and English languages ${ }^{\circ 6}$ and another six only extend their discussion of interpreters in direct response to applicant submissions, eg. 'the applicant also stated the interpreter during the Departmental interview was very 'slow' and had to take a lot of notes and perhaps did not note down everything she said. ${ }^{67}$ In only three decisions do decision-makers offer extra, unsolicited, descriptions about interpreter participation. ${ }^{68}$ For example, Syme describes interpreting in his decision regarding a Vietnamese applicant:

Both of the Tribunal hearings were conducted with the assistance of an interpreter in the Vietnamese and English languages. The first hearing was adjourned when the interpreter [sic] no longer available. For the first

\footnotetext{
${ }^{63}$ Eg 1401357 [2014] RRTA 836 (7 November 2014) at 63.

${ }^{64} \mathrm{Eg} 1300325$ (Refugee) [2015] AATA 3147 at. 80.

651403553 (Refugee) [2015] AATA 3238 (29 July 2015); 1319789 (Refugee) [2015] AATA 3453 (25 September 2015); 1415919 [2015] RRTA 66 (12 February 2015); 1411183 (Refugee) [2015] AATA 3619 (5 November 2015). The last of these involved an applicant from Ghana, who potentially may be assumed to speak English, as it is a national language. However, it should be noted that around 80 languages are spoken in Ghana and English is not spoken universally, and normally spoken as a second language. See https://www.ethnologue.com/country/GH/languages.

661313904 (Refugee) [2015] AATA 3336 (21 August 2015).

${ }^{67} 0908977$ [2010] RRTA 512 (28 June 2010), para 38.

68 1401357 [2014] RRTA 836 (7 November 2014); 1313153 [2014] RRTA 463 (26 May 2014); 1001085 [2010] RRTA 551 (2 July 2010).
} 
hearing the interpreter was via telephone. For the second hearing an onsite interpreter was present for the majority of the hearing and an interpreter via telephone assisted for the final 20 minutes when the onsite interpreter was no longer available. ${ }^{69}$

There is similarly little mention of legal representation. Where migration practitioners are mentioned, their involvement is usually limited to describing a written submission they provide. Even in this case, 'utterance autonomization' is common - the text itself is identified as subject, rather than its creator, ${ }^{70}$ for example, 'The submissions state that the delegate made an error'. ${ }^{71}$ In one case, where it was clear that a representative was involved, agency or responsibility for creating the written submission is directly reassigned to the applicant themselves - 'the applicant provided the following reply'. ${ }^{72}$ Of the seven decisions where it appears that applicants were unrepresented, only one decision explicitly acknowledges this lack of representation and the potential impact it could have on the applicant's participation or explanations. ${ }^{73}$ This means that in most decisions, applicants are assigned full responsibility for deficiencies in how they develop the refugee narrative, or how they respond to concerns, without reflection on how professional assistance may (or may not) have shaped these. While these discursive choices echo conventions in judicial decision-making, the effect of these types of framing is that they background or minimise the impact of the representative (or lack thereof) on text production and on the application and appeal processes more generally. ${ }^{74}$

Across the decisions, witnesses and their evidence are closely aligned with the applicant, both in the case of expert and lay witnesses. If the applicant is not more generally believed,

691313153 [2014] RRTA 463 (26 May 2014), para 8.

70 van Leeuwen (1996), p 60.

${ }^{71} 1406144$ (Refugee) [2015] AATA 3154 (9 July 2015) at 25, emphasis added.

721102389 [2011] RRTA 525 (28 June 2011) at 64, emphasis added.

73 The acknowledgement appears in 1502929 (Refugee) [2015] AATA 3409 (4 September 2015). The other decisions are 1401357 [2014] RRTA 836 (7 November 2014); 1210091 [2013] RRTA 344 (22 May 2013); 1415919 [2015] RRTA 66 (12 February 2015); 0908977 [2010] RRTA 512 (28 June 2010); 1204285 [2012] RRTA 701 (9 July 2012); 1411183 (Refugee) [2015] AATA 3619 (5 November 2015).

${ }^{74}$ For examinations of the roles professional representatives play in shaping the refugee narrative and contributing to the application and appeals processes more generally, see, eg, Smith-Khan (2019c); Vogl (2013). 
their witnesses, or the evidence they give, provide no additional weight for the applicant. ${ }^{75}$ This creates a problematic 'Catch-22', in which evidence is required to (re)establish applicant credibility, but if the applicant's credibility is in doubt, witness evidence risks being discounted too.

\section{Applicants}

Decision-makers' presentations of asylum-seekers were also reflective of the way they were conceptualised in the Guidelines. Decisions refer to them as 'the applicant', and describe the applicant as giving evidence. However, again, there is some lexical variety, for example whether decision-makers favour either marked or more neutral terms to describe the applicant's speech, in constructions such as 'the applicant claimed' or, contrastingly, 'the applicant said'. These choices obviously served to add evaluative meaning to their reports, but all fell within the broader discursive positioning of the applicant as text creator and communicator.

Overall, these representations demonstrate that the decision-makers appear to be influenced by or to share the institutional discourse about their role and the roles of other participants. At the same time, the fact that they vary in some of their choices, for example in the ways they refer to themselves or the degree to which they acknowledge the participation of other actors, serves to undermine the assumption that they are neutral or uniform actors and communicators. This clearly demonstrates the variety of their communicative choices in their written decisions. By extension, arguably, this also indicates that they would be equally diverse as communicators beyond these texts, for example, in the way they conduct hearings. ${ }^{76}$ Unsurprisingly, perhaps, research interviews with migration agents also confirm this variety, reporting diversity across

\footnotetext{
${ }^{75}$ Although see an exception in the comparative analysis of outlier decisions below.

${ }^{76}$ Existing research supports this assumption. Findling and Heydon (2016) identify variation amongst tribunal members in the way they present the hearing preamble, the level of formality with which they conduct the hearing, how and whether they explain the hearing's purpose, and their style of questioning.
} 
everything from decision-maker accent, to body language, to the way different tribunal members manage the participation of interpreters and migration agents. ${ }^{77}$

It may be surmised that the discourse of the Guidelines influences the decision-makers or that the decision-makers and Guideline drafters are influenced by or draw on a shared institutional culture. However, further connections can be noted when individual decisions are examined. ${ }^{78}$ Most importantly, however, the below exploration demonstrates more concretely some of the challenges arising from assuming decision-makers can be uniform and neutral, and from the limited and problematic beliefs about linguistic and other forms of diversity within the guidance.

\section{Individual Decisions: Credibility, Understanding and Accommodating Diversity}

It is not inherently problematic that the Guidelines suggest applicants' thoughts and behaviour are influenced by their backgrounds. What is concerning - and what the below analysis seeks to demonstrate - is first, that the unequal emphasis on applicants' difference (in contrast to decision-makers) can lead to an essentialization of their diversity, with an overemphasis on one single characteristic, at the expense of all the other facets of their identities and lives. Second, there is scope for oversimplified or stereotypical understandings of the way cultural, linguistic or social backgrounds or group membership affect an applicant's behaviour. This means that the way they actually do feel and act (either during interviews, or in their life) appears implausible or otherwise lacks credibility against the other indicators. This is especially problematic when the influences of the decision-maker's own background in informing these evaluations remain under-acknowledged in the discourse.

The first decision of interest regards an applicant from India whose claim was based on his homosexual identity. ${ }^{79}$ The decision-maker reported raising a number of credibility-related

\footnotetext{
${ }^{77}$ Smith-Khan (2019c).

78 These first two decisions presented below are analysed and discussed in greater detail in Smith-Khan, (2017a).

791319407 [2014] RRTA 705 (18 September 2014).
} 
concerns with the applicant, who provided a range of what could be considered largely sociolinguistic explanations for each one. For example, the decision-maker found it implausible, if the applicant was really gay, that he would not seek out other homosexual people quite soon after arriving in Australia, rather than after some delay. The decision-maker described this as a 'failure to attempt to meet other homosexuals prior to 2012', indicating a belief that there was only one appropriate and plausible course of action. ${ }^{80}$ The applicant explained the delay by pointing to his status as an international student, his limited English, limited income and cultural difference. These explanations were largely rejected, and indeed in later references to them, the decision-maker discards the cultural and linguistic ones, referring only to income and student status. ${ }^{81}$

The expectation that because he was homosexual, the applicant should have sought out relationships is problematic for a range of reasons beyond the dismissal of these legitimate explanations. It denies him the individual right of choice about how he should behave in his life, assigning his sexual identity as (what should be) the sole driving influence for his behaviour, and attaching very narrow, specific conduct assumptions to this identity. This similarly undermined his explanations as to why he had chosen to live with other Indians (who he met through family contacts and online, ie drawing on his social resources) despite his fear of being 'outed' in the Indian community. In his exploration of mobility and sexuality, Stychin acknowledges these types of challenges for racial and ethnic minorities, where migration, while potentially offering protection and opportunity for sexual minorities, often also involves an increase in 'surveillance from the state, as well as from within migrant communities' ${ }^{82}$ Particularly relevant for the applicant in this case, Stychin also notes that language barriers may create 'a severe constraint on participation and acceptance' and that (institutionally) acceptable

\footnotetext{
801319407 [2014] RRTA 705 (18 September 2014) at 20, emphasis added

${ }^{81} 1319407$ [2014] RRTA 705 (18 September 2014) at 20.

${ }^{82}$ Stychin (2000), p 606.
} 
sexual identities may be exclusionary, favouring 'modernist, Eurocentric' assumptions, where 'a "Stonewall" model of liberation based upon the closet and "coming out" is understood as the global norm for homosexual identities. ${ }^{83}$

The generally very scant inclusion of language considerations in the Guidelines may perhaps have influenced the way the applicant's explanations about feeling uncomfortable discussing sexual encounters in front of a female Indian interpreter were dismissed, when he attempted to explain apparent inconsistency and vagueness. Still, this treatment of his concerns is particularly troubling considering that interpreter gender choice in sensitive applications is one of the only considerations the Guidelines do explicitly raise regarding the potential for communication issues. ${ }^{84}$ Further the topics covered in the hearing, where the decision-maker asked detailed questions about sexual encounters, also contravened a separate set of Gender Guidelines which instruct that sexual identity rather than sexual acts should be explored in these types of cases. ${ }^{85}$

Another decision, involving a Christian applicant from Egypt,${ }^{86}$ also involved the applicant being challenged on multiple points of perceived inconsistency as well as implausibility in his narrative. He provided explanations for each of these, once again often based in language and culture. This included him suggesting that questioning style and interpreting may have accounted for apparent inconsistencies across different interviews and written documents. He also raised his own English language proficiency to explain variation in terms. For example, when he had used 'arm' to describe an injury in a written statement, but the word 'shoulder' appeared in a medical certificate, this was judged as an inconsistency affecting his credibility.

\footnotetext{
${ }^{83}$ Stychin (2000), p 606.

84 'Claims relating to a person's sexual orientation or to sexual assault or domestic violence, require particularly sensitive investigation. The tribunal should consider who is present at the time the evidence is to be given and whether it would be appropriate for an interpreter of a particular gender to assist with the hearing.' Guidelines, para 24.

85 AAT, Migration and Refugee Division, Guidelines on Gender (2015), para 21. Available at <https://www.aat.gov.au/landing-pages/practice-directions-guides-and-guidelines/guidelines-on-gender> .

861102389 [2011] RRTA 525 (28 June 2011).
} 
When the decision-maker raised this concern, the applicant explained that his English vocabulary was limited and that he had completed the written statement with his lawyer without the assistance of an interpreter. It should have been relatively unsurprising that as a second language speaker of English, the applicant had knowledge of the broader term 'arm', but not the more specific term, 'shoulder'. Yet, this explanation, when considered alongside other issues, was not accepted.

When explaining why he had at one point described a particular man as answering the door and at another point said that the man's mother had answered, he pointed to difference in housing design, and a cultural/religious custom whereby occupants of a house (especially women) would ascertain the caller's identity behind the closed door before deciding whether to open it or let another member of the household do so. This detail, which may have seemed banal to the applicant when initially telling his story, became another reason for negatively assessing his credibility, his sociocultural explanation discounted.

Finally, the decision-maker also questioned the plausibility of the applicant going alone to meet the man who had attacked his brothers. The applicant's explanation for choosing to do this, that he had believed that this was less likely to intimidate the man and escalate tensions, was similarly dismissed as unbelievable. This response not only discounts the applicant's sociocultural explanations, but also denies him the right to have personal idiosyncrasies that affect his choices, similar to the approach taken in the first case study. Behaving in ways that the decision-maker deems unwise or irrational are therefore beyond the scope of plausible behaviour for asylum-seekers and can undermine their overall credibility. This is a common issue identified in other studies on asylum decision-making. Researchers argue that deciding whether particular behaviour is plausible involves trying to make sense of situations outside decision-makers' own experience, meaning that they must draw on what are problematically considered 'common sense' assumptions or stereotypes about what they would do or how they 
would react. ${ }^{87}$ Other research similarly identifies a range of challenges when determining whether asylum-seekers responded in plausible ways to claimed risks of harm, discussing how difficult it may be for decision-makers to relate to asylum-seekers when they have very different life experiences that inform how they would respond to dangerous situations. ${ }^{88}$

These two unsuccessful attempts to overcome credibility concerns can be contrasted with the approach taken in two outlying successful appeals included in the study. ${ }^{89}$ Notable in both those cases were that such sociocultural and linguistic arguments as those described in the above examples were (apparently) not raised. Rather, both decision-makers relied on relevant although not unequivocal third-party country information to conclude that dangers existed for the applicants, a Sinhalese and a Tamil Sri Lankan, despite their decision to reject as not credible parts of the applicants' claims. Further, unlike the examples presented above, rather than being concerned with fragmented decontextualized inconsistencies, or those in peripheral details, the credibility concerns the decision-makers had actually related more centrally to the persecution-related elements of the applicants' claims, such as the level and type of harm they feared or had already experienced, and the reasons for these fears. However, rather than rejecting the claims outright based on their ongoing doubts about the credibility of some of these elements, both decision-makers were able to discern protection needs regardless of not completely accepting the applicants' entire claims.

Further, in the case of the Tamil applicant, the decision-maker acknowledges some responsibility for gathering evidence. He describes particular parts of the applicant's evidence as being 'vague' and lacking detail, but acknowledges his own role in needing to 'question the

\footnotetext{
${ }^{87}$ Herlihy et al (2010).

${ }^{88}$ See Evans Cameron (2008).

891313904 (Refugee) [2015] AATA 3336 (21 August 2015); 1406144 (Refugee) [2015] AATA 3154 (9 July 2015). The third successful appeal, 1408142 (Refugee) [2015] AATA 3256 (7 August 2015), mentions credibility on a number of occasions, but evaluates them positively (e.g. the tribunal member found the applicant to be a credible witness, and referred to a number of supporting documents as being credible evidence). In other words, this decision was a true outlier, as the applicant did not have to overcome credibility concerns.
} 
applicant at length about issues in order to clarify matters' ${ }^{90}$ This contrasts with the negative reception of apparent vagueness in the Indian applicant's responses, where these arose in part due to the decision-maker's problematic exploration of sexual acts, as discussed above.

Finally, in both successful appeals, the decision-makers were more open to accepting documentary evidence that in other cases may have been rejected based on other credibility concerns. For example, in the Sinhalese applicant's case, medical documentation was accepted and used to interpret the impact of the harm he feared. ${ }^{91}$ This is contrasted with medical certificates provided in the Indian applicant's case to evidence both the applicant's own psychological issues, and to explain inconsistencies in a witness's testimony based on longstanding psychological conditions. In the Indian applicant's case, this evidence was not given weight due to the more general finding that the applicant was not a 'witness of truth'. 92

It is impossible to know the full story for any of these applicants and the analysis here only addresses a few aspects of their respective review decisions. However, the common pattern across both unsuccessful cases is that when the asylum-seekers and/or their representatives draw on language or culture to respond to credibility concerns, these explanations are rejected. Those relating to conduct in the events making up the refugee's story or more generally regarding their behaviour outside the hearing are especially unlikely to be accepted. This appears to be in line with the fact that the Guidelines' instructions regarding the social and cultural background of the applicant almost exclusively focus on their conduct in the hearing, and neglect to address the way social and cultural factors may lead to different perspectives and behaviour in their refugee narratives and outside life. Further, even when instructing on the conduct of the hearing, there is very little reference to language at all, suggesting that it is not a major factor that needs accommodating. What is also clear from these examples is that

\footnotetext{
901406144 (Refugee) [2015] AATA 3154 (9 July 2015), para 51.

${ }^{91} 1313904$ (Refugee) [2015] AATA 3336 (21 August 2015), eg paras 36, 38.

921319407 [2014] RRTA 705 (18 September 2014), eg para 60.
} 
while uniformity and neutrality are expected, decision-makers must inevitably draw on their own expectations and assumptions about what is reasonable and rational.

Further, problematically, many of the individual credibility issues identified in the negative decisions seem insignificant by themselves, but the cumulative effect of multiple issues appears to negatively influence decision-makers' receptiveness of explanations given in response to each individual one. ${ }^{93}$ The Indian applicant was found to not be a 'witness of truth' and the Egyptian applicant was found to lack 'overall' or 'general' credibility, and these findings then had an impact on the acceptance of other elements of their claims or responses to credibility concerns. This suggests that once a decision-maker suspects an applicant, it will be difficult to convince them to open their mind to the above types of arguments, especially where these arguments challenge the decision-makers' own underlying assumptions and perspectives and push the boundaries of what the Guidelines present as important considerations. This is an issue that qualitative interviews with migration practitioners confirm, many stressing the importance of quickly intervening to address such issues before finishing the hearing to minimise the chance of this negative attitude becoming set in the decision-maker's mind.${ }^{94}$ Obviously, this strategy is unlikely to be open to asylum-seekers who do not have high quality, or any, professional assistance.

\section{Language Ideologies in Credibility Assessment Discourse}

The above analysis suggests the existence of a number of language ideologies upon which the legitimacy of the current system of credibility assessment relies. Firstly - and most crucially - the institutional discourse relies on an understanding that asylum-seekers produce texts more or less in isolation: that they are the sole creators of the refugee narrative as a whole, and of the many different written and spoken texts that make it up. At the very least, it assumes that they

\footnotetext{
93 This reflects findings in Luker (2013) in her interviews with RRT members.

${ }^{94}$ Smith-Khan (2019c).
} 
are the 'principals' of the texts, responsible for what is said, regardless of whether they only use their own voice or words to produce these texts, or whether other speakers, writers or questioners are involved. ${ }^{95}$ Based on this belief, these texts can then be tested individually and as a whole against a set of indicators which are each related in some way to how the text is performed, created or experienced (e.g. internal and external credibility, plausibility, detail, applicant's demeanour etc), and on the basis of these tests, the asylum-seeker can be fairly discredited. The process of applying these indicators relies on further beliefs about communication that are also connected with or dependent on sole authorship. For example, discrediting communication based on internal inconsistency relies on the belief that if a story is true, its narrator will recount it consistently over time, and if it is inconsistent, this is because the person is lying, and not due to the impact of time, context, third party involvement or any other external factor. ${ }^{96}$ Inconsistencies may centre on decontextualized fragments, even single words, as in the example of the Egyptian applicant's 'inconsistent' uses of 'arm' and 'shoulder', where the contextual factors of lack of interpreting and limited English proficiency are discounted..$^{97}$

Likewise, measuring credibility against an imagined and idealised level of detail - not too much, not too little - and assuming that truth can be discerned from the narrator's body language or expression, similarly relies on specific beliefs about communicative behaviour that exclude the role of the interlocutor and observer, third party contributions, and context.

The 'arm' versus 'shoulder' issue also exemplifies how these measurements may draw on problematic beliefs about language proficiency. For example, individuals with some basic level

\footnotetext{
${ }^{95}$ For a detailed explanation of the concept of 'principal' as a type of actor within a 'participation framework', see Goffman (1981). Zambelli (2017), p 17, argues it is particularly ironic that what is considered refugee speech in reality often is 'spoken' by third parties and 'the asylum seeker is almost never heard speaking in his or her own voice.'

${ }^{96}$ Eades (2013), para 11.4.1.

${ }^{97}$ See Eades (2013) ch 11 for similar examples of decontextualization and recontextualization used to undermine witness credibility in court.
} 
of English proficiency may be expected to be able to provide accurate and consistent information in English, despite the fact that their proficiency may not be sufficient for legal and bureaucratic settings. ${ }^{98}$ This draws on a misunderstanding of language proficiency or bilingualism as a binary. This is the belief that someone either can or cannot speak and understand a particular language, rather than viewing proficiency as nuanced and diverse, as argued by sociolinguist scholarship. Researchers have found that this belief can mean that based on having informal, basic levels of English, defendants may be unfairly assessed as not requiring an interpreter in court, or that police interviews conducted without interpreting are admissible evidence. ${ }^{99}$ It may also explain why the Indian asylum-seeker's arguments about limited language proficiency as a reason for some of his choices are not accepted, and later references to his reasoning erases the mention of language proficiency altogether. ${ }^{100}$

His arguments may have also been undermined by a related language ideology regarding language testing as an indication of high and universal language proficiency: as an international student he would have had to pass an English exam to gain entrance to his degree. ${ }^{101}$ While not addressing this point explicitly, the decision-maker describes him as 'an intelligent educated and resourceful individual' ${ }^{102}$ to dismiss arguments related to lack of knowledge regarding protection visa options. Presenting himself as proficient when applying for his student visa and later as lacking proficiency for the purposes of defending his credibility in his asylum appeal could thus actually further undermine his credibility, as an apparently inconsistent and deceptive representation of his skills.

\footnotetext{
98 Eades (2012); Angermeyer (2015).

${ }^{99}$ For a similar example in the Belgian asylum context, see Maryns (2006), ch 2. For other legal contexts, see, e.g. Eades (2003), (2013) ch 11, Angermeyer (2015).

${ }^{100}$ See above analysis. The applicant cites limited English language proficiency as a reason for not dating on arrival in Australia.

${ }^{101}$ For a critical examination of ideologies related to language proficiency and testing, see Piller (2016).

1021319407 [2014] RRTA 705 (18 September 2014), para 66.
} 
Although there is no specific indication based on the official summaries of the hearings examined above, these beliefs about language proficiency can sometimes also mean that even where partially bilingual people are successful in gaining interpreting assistance, they may be treated with suspicion, based on a misconception that they are using an interpreter for some other sinister motive, rather than real need. ${ }^{103}$

The minimal recognition given to the contributions of third parties such as interpreters and legal representatives can be said to both reinforce and result from the overarching sole authorship language ideology, and also the ideologies regarding language proficiency and decontextualized fragments. The presumption that different decision-makers can be guided or controlled to act in uniform ways is another necessary component of this sole-authorship ideology, shaped also by the belief that procedures can be designed and implemented in such a way as to completely control or neutralise the impacts of interlocutor interaction, linguistic choices and social dynamics, and thus somehow distil asylum-seeker communication from social interaction in a true or pure form. As discussed in more detail below, the belief that a true meaning exists separately, awaiting distillation, is fundamentally inconsistent with the linguistically supported view that language arises interactionally, and meaning is coconstructed through interaction.

Further, once these texts are produced, it is assumed that, unlike the culturally-rooted asylum-seekers, acultural decision-makers, as expert and procedurally-controlled interlocutors and thinkers, are capable of applying these credibility tests objectively, and therefore consistently, once again with no variation from person to person. This positions them as privileged knowers when determining and evaluating socially, culturally or linguistically relevant considerations, whether these relate to the conduct of procedures, or elements of the asylum-seekers' lived experiences that make up the narrative. Where asylum-seekers'

${ }^{103}$ See discussion and examples in Angermeyer (2015). 
explanations or experiences do not draw on understandings or ways of knowing that are conceivable or familiar to the decision-maker, or they do not communicate these explanations in a form that the decision-maker expects, their accounts or arguments are likely to be dismissed as implausible or in some other way unbelievable. ${ }^{104}$ The application of the credibility indicators entails evaluative processes undertaken by individual decision-makers who, even if they act in complete good faith and strive to be objective, are nonetheless subjective social actors, just like the applicants and other participants, and inevitably must draw on their own social and cultural experiences and beliefs about particular groups, their language and their behaviour to inform their evaluations. As discussed earlier, these beliefs are further informed by institutionally-sanctioned documents that provide generalizations about the behaviour and experiences of people from particular groups; documents that are also produced by socially and politically-situated actors.

These ideologies create an important framework upon which one final ideology relies: the belief that refugee visa decision-making bodies, through set procedures applied by individual decision-makers, can obviate the impacts of social and linguistic diversity in order to evaluate objectively and justly the credibility of asylum-seekers and their claims.

However, what is known in sociolinguistics about how communication works challenges the ideologies discussed above. First, the texts produced in the context of asylum applications and appeals are the result of socially situated encounters between multiple participants. These include decision-makers, who ask questions and determine the timing, length and content of interviews. In the Australian context, individual tribunal decision-makers have been found substantially to vary in the way they conduct hearings and apply credibility indicators. ${ }^{105}$ This is similarly reflected in the comparative analysis of two successful and two unsuccessful cases

\footnotetext{
${ }^{104}$ In terms of form, RRT members have identified excessive displays of emotion as suspect behaviour in hearings, and migration lawyers report alerting their clients regarding this issue. See Luker (2013); Smith-Khan (2017). ${ }^{105}$ Findling and Heydon (2016); Luker (2013).
} 
above. Interpreters are fully-fledged social actors, whose presence, conduct and perceived identity may influence the behaviour of other participants, and who - putting aside any issue of competence - adopt a range of linguistic decisions in their interpreting. ${ }^{106}$ Migration lawyers' advice, written and oral contributions, and even their social resources (such as their professional reputation and relationships with decision-makers) also have an impact, when assistance is in fact available at all. ${ }^{107}$ Further, rather than being produced in a vacuum, the form and content of these texts are institutionally dictated, must comply with complex procedural requirements, and must be made to fit within a legal definition of who constitutes a refugee for the purpose of granting an Australian protection visa. ${ }^{108}$

The ideologies that emerge from this analysis echo the findings of a study by Shonna Trinch, exploring the creation of domestic violence protection order affidavits in the US. ${ }^{109}$ Trinch identifies a similar 'narrator-as-sole-author' ideology. Like the arguments above, she challenges this ideology with reference to a range of sociolinguistic factors, emphasising the impact of interlocutor collaboration, as well as contextual constraints on narrative creation. As Trinch argues, 'interpretive ideologies of textual ownership and textual purpose are exploitable to discredit narrators, when they are used to challenge narrator-credibility'. ${ }^{110}$ This argument is equally relevant in the context of migration decision-making, based on my study, and is arguably even more problematic in this setting, where there are serious concerns about a

\footnotetext{
106 Tipton (2008); van der Kleij (2015).

${ }^{107}$ Hambly (2019).

${ }^{108}$ For a discussion on the tensions between institutional and legal requirements and free narrative production, see for example Vogl (2013).

109 Trinch (2003).

110 Trinch (2003) p 50. See also Piller (2001), p 272, who draws similar conclusions in relation to language testing in naturalization procedures, arguing that the "legislative framework shifts [the text creation] burden unilaterally onto the naturalization applicant while "the right to speak" and "the power to impose reception"...is exclusively granted to the naturalization officer.'She argues that these contradict and suggest an absence of 'discourse analytic experitse in (cross-cultural) communication that might have guided the writing of a text about language and language testing'.
} 
growing culture of disbelief, and where senior government officials have been accused of interfering with decision-maker independence. ${ }^{111}$

Therefore, in addition to the many criticisms that credibility assessments have attracted in existing scholarship, this paper argues that they are substantially undermined by the multiple problematic language ideologies on which they rely. Each credibility indicator measures texts or elements of texts that are impacted by social interaction and embedded within the confines of institutional processes and shaped by legal requirements. Whether or not an asylum-seeker 'passes' as authentic is largely beyond their individual control. ${ }^{112}$

Overall, this demonstrates an inequality between the decision-maker (and institution) and the asylum-seeker, with the former being deemed responsible for determining the merit of the latter's social, cultural and linguistic arguments, based on whether the asylum-seeker's meaning-making accords with the individual decision-maker's and their institution's 'common sense' understandings of the world. ${ }^{113}$

Therefore, while the institutional discourse frames the spoken and written texts against which credibility is measured as inherently produced and controlled by the individual asylumseeker, this is far from the truth. In reality, these texts result from institutional structures, and within these, from the interactions and contributions of multiple actors, both in their initial production and in the way they are reworded and interpreted in the process of drafting decisions documents. This presents significant challenges to the acceptability and legitimacy of credibility assessments in their current form as fair and objective tools.

\footnotetext{
${ }^{111}$ In the Australian context, the federal government has appointed 65 members with close political connections, and not renewed the contracts of many other experienced and appropriately qualified members, making public criticisms of politically unfavourable decisions. See Hobbs and Williams (2019); and online reports from a recent investigation, eg https://www.crikey.com.au/2019/09/24/a-whos-who-in-the-aat-zoo/; https://www.crikey.com.au/2019/09/24/a-whos-who-in-the-aat-zoo/.

112 Trinch (2003).

${ }^{113}$ For an in-depth discussion of hermeneutic marginalization and its role in testimonial inequality, see chapter 7 of Fricker (2007).
} 


\section{Implications for Credibility Assessments}

Refugee visa decision-making is a notoriously challenging activity, and existing research in Australia has revealed a level of uncertainty and lack of confidence among decision-makers in the assessment of credibility as part of this process. ${ }^{114}$ Asylum-seekers often have little more than their story to support their application and at first glance, credibility assessments such as the ones explored here, offer an apparently detailed and consistent mechanism for fairly processing claims. Moreover, the prevalence and popularity of these types of credibility assessments are particularly unsurprising given the political culture in many countries of the global north, Australia included, which increasingly emphasises the need to secure borders and demonises irregular migration. In this context, credibility assessments appear an attractive means to restrict entry and sort between individuals who merit protection and those who are dishonest and therefore undeserving. ${ }^{115}$ However, as argued above, these assessments rely on particularly problematic language ideologies. It is then unsurprising that explanations for apparent credibility issues which are based on conflicting understandings of how communication works are rarely accepted. Acknowledging the misconceptions about communication, narrative production, and evaluative processes on which these assessments rely effectively challenges their legitimacy as fair tools capable of ensuring just procedures.

This finding has implications for the fair conduct of refugee visa decision-making, both within Australia and overseas. At the level of individual decision-making, greater sensitisation regarding intercultural communication and critical self-reflexivity and awareness relating to one's own social and cultural influences are essential. ${ }^{116}$ At the institutional level, a number of measures addressing legal and procedural inequality have been recommended, which have the potential to help address some of the concerns arising in the above analysis. These include

\footnotetext{
${ }^{114}$ Luker (2013).

${ }^{115}$ Even though refugee status should not be dependent on honesty or merit. See Hathway and Foster (2014), para 2.6 .

${ }^{116}$ As suggested, for example, by Macklin (1998); Noll (2005).
} 
adopting a narrow approach to credibility assessment: limiting this to the admissibility of individual pieces of evidence, rather than 'general'/applicant credibility. Developing a more explicit and generous policy of applying the benefit of the doubt could help limit the impact of negative credibility findings, as exemplified in the approach adopted in the two successful appeals examined above. ${ }^{117}$

Also of potential benefit would be more explicit legally-prescribed opportunities for applicants (or their representatives) to respond to credibility concerns, with greater official recognition of the types of cultural and linguistic issues raised in this study. To assist with this, an expansion or clarification of the tribunal decision-makers' inquisitorial duties could help to encourage more meaningful inclusion of evidence related to language and communication. ${ }^{118}$ This could also entail more clearly requiring decision-makers to take responsibility for obtaining suitable evidence, meaning that they may need to restructure their questioning styles, and make better allowances for the impact of 'potential distortions in testimony that arise from cultural, psychological, educational and distance barriers over time'. ${ }^{119}$ Amendments to legislation to increase the rights of asylum-seekers to determine the conduct and content of hearings could also assist, along with the right to have a legal representative participate, and increased public funding to make this right realizable in practice.

However, even if political and institutional will aligned such that all these recommendations were implemented, the issue remains that credibility construction is wrongly attributed to the asylum-seeker acting - or speaking - alone. While this is undoubtedly an attractive approach to rationalise decisions, it leaves scope for unfair outcomes and is especially problematic in an

\footnotetext{
${ }^{117}$ See also recommendations in Kagan (2003); Sweeney (2009); Luker (2013). Byrne (2007) similarly suggests sharing the burden of proof more clearly between the applicant and the decision-maker 118 Coffey (2003).

${ }^{119}$ Byrne (2007), p 637.
} 
institutional culture which frames asylum-seekers as suspicious in the first place and thus undermines their ability to mobilise identities which positively contribute to their credibility. ${ }^{120}$

Given the current political climate, reform prospects appear bleak. However, there are a few clear opportunities stemming from this research. It contributes to a growing evidence base upon which to publicly advocate for decreasing reliance on credibility as a reason for rejecting protection visa applications. The research findings also underline the need for continued critical examination of institutional and public discourse that foreground or problematize refugee credibility. The legitimacy of these processes in their current form relies on misconceptions that can only be challenged by first being identified and brought to the attention of the public. Finally, the study creates an impetus for continued investigations better to understand and emphasise the impact of third parties in the application and appeals processes who, as we have seen, may go largely overlooked and undervalued in official discourse. These steps would go some way to addressing the incredibility of credibility assessments.

Table 1: Tribunal Decisions

\begin{tabular}{|c|c|c|c|}
\hline CITATION & DECISION- & SUCCES & APPLICANT ORIGIN \\
\hline 1411183 (Refugee) [2015] AATA 3619 (5 November 2015) & Short & SFUL & Ghana \\
\hline 1319789 (Refugee) [2015] AATA 3453 (25 September & Short & No & No \\
\hline 2015) & & No & \\
\hline 1502929 (Refugee) [2015] AATA 3409 (4 September & Syme \& Eteuati & No \\
\hline 2015) & & Yes & Sri Lanka \\
\hline 1313904 (Refugee) [2015] AATA 3336 (21 August 2015) & Webb & Yes & Sri Lanka \\
\hline 1408142 (Refugee) [2015] AATA 3256 (7 August 2015) & Carlton & \\
\hline
\end{tabular}

${ }^{120}$ For detailed explorations of how identity resources may impact speaker credibility, see Fricker (2007), ch. 1, and Smith-Khan, (2019a). 


\begin{tabular}{|c|c|c|c|}
\hline 1403553 (Refugee) [2015] AATA 3238 (29 July 2015) & Short & No & Sri Lanka \\
\hline 1319097 (Refugee) [2015] AATA 3247 (24 July 2015) & Carlton & No & Sri Lanka \\
\hline 1406144 (Refugee) [2015] AATA 3154 (9 July 2015) & Joliffe & Yes & Sri Lanka \\
\hline 1300325 (Refugee) [2015] AATA 3147 (7 July 2015) & Henry & No & India \\
\hline 1315946 (Refugee) [2015] AATA 3139 (6 July 2015) & Carlton & No & Sri Lanka \\
\hline 1315977 [2015] RRTA 160 (20 April 2015) & Joliffe & No & Sri Lanka \\
\hline 1415919 [2015] RRTA 66 (12 February 2015) & Cullen & No & China \\
\hline 1401357 [2014] RRTA 836 (7 November 2014) & Bray & No & Malaysia \\
\hline 1319407 [2014] RRTA 705 (18 September 2014) & Millar & No & India \\
\hline 1313153 [2014] RRTA 463 (26 May 2014) & Syme & No & Vietnam \\
\hline 1300938 [2013] RRTA 410 (13 June 2013) & Millar & No & Bangladesh \\
\hline 1210091 [2013] RRTA 344 (22 May 2013) & Cosentino & No & India \\
\hline 1210413 [2013] RRTA 172 (18 February 2013) & Murphy & No & Zimbabwe \\
\hline 1206873 [2012] RRTA 828 (5 October 2012) & Godfrey & No & Sri Lanka \\
\hline 1204285 [2012] RRTA 701 (9 July 2012) & Hely & No & Nigeria \\
\hline 1108620 [2011] RRTA 1055 (6 December 2011) & Grau & No & Zimbabwe \\
\hline 1100115 [2011] RRTA 574 (8 July 2011) & Hely & No & Lebanon \\
\hline 1102389 [2011] RRTA 525 (28 June 2011) & Hely & No & Egypt \\
\hline 1001085 [2010] RRTA 551 (2 July 2010) & Wilson & No & China \\
\hline 0908977 [2010] RRTA 512 (28 June 2010) & Derewlany & No & China \\
\hline 0801661 [2008] RRTA 244 (23 June 2008) & Younes & No & China \\
\hline 0801041 [2008] RRTA 210 (10 June 2008) & Younes & No & China \\
\hline
\end{tabular}




\section{References}

\section{Secondary Sources}

Philipp S Angermeyer (2015) Speak English or What? Codeswitching and Interpreter Use in New York City Courts, Oxford University Press.

Jan Blommaert (2001) 'Investigating Narrative Inequality: African asylum seekers' stories in Belgium' 12(4) Discourse \& Society 413.

Carol Bohmer and Amy Shuman (2007a) 'Producing epistemologies of ignorance in the political asylum application process' 14(5) Identities: Global Studies in Culture and Power 603.

Carol Bohmer and Amy Shuman (2007b) Rejecting Refugees: Political Asylum in the $21^{\text {st }}$ Century, Routledge.

Rosemary Byrne (2007) 'Assessing Testimonial Evidence in Asylum Proceedings: Guiding Standards from the International Criminal Tribunals' 19(4) International Journal of Refugee Law 609.

Joyce Chia, Jane McAdam and Kate Purcell (2014) 'Asylum in Australia: "Operation Sovereign Borders” and International Law’ 32 Australian Yearbook International Law 33.

Guy Coffey (2003) 'The Credibility of Credibility Evidence at the Refugee Review Tribunal' 15 International Journal of Refugee Law 377.

Mary Crock and Laurie Berg (2011) Immigration, Refugees and Forced Migration: Law, Policy and Practice in Australia, Federation Press.

Diana Eades (2013) Aboriginal Ways of Using English, Aboriginal Studies Press.

Diana Eades (2003) 'Participation of Second Language and Second Dialect Speakers in the Legal System’ 23 Annual Review of Applied Linguistics 113.

Diana Eades (2012) 'The social consequences of language ideologies in courtroom cross-examination' 41(4) Language in Society 471.

Marita Eastmond (2007) 'Stories as Lived Experience: Narratives in Forced Migration Research' 20(2) Journal of Refugee Studies 248.

Hilary Evans Cameron (2008) 'Risk Theory and "Subjective Fear": The Role of Risk Perception, Assessment, and Management in Refugee Status Determinations' 20(4) International Journal of Refugee Law 567.

Danielle Every and Maria Augoustinos (2008) “"Taking advantage” or fleeing persecution? Opposing accounts of asylum seeking' 12(5) Journal of Sociolinguistics 648.

Norman Fairclough (2001) 'Critical discourse analysis as a method in social scientific research' in R Wodak and M Meyere (eds), Methods of Critical Discourse Analysis, SAGE.

Jessica Findling and Georgina Heydon (2016) 'Questioning the evidence: A case for best-practice models of interviewing in the Refugee Review Tribunal' 26(4) Journal of Judicial Administration 19.

Lorna Fox O'Mahony and James A Sweeney (2010) 'The exclusion of (failed) asylum seekers from housing and home: Towards an oppositional discourse' 37(2) Journal of Law and Society 285. 
Miranda Fricker (2007) Epistemic Injustice: Power and the Ethics of Knowing, Oxford University Press.

Daniel Ghezelbash (2018) Refuge Lost: Asylum Law in an Interdependent World, Cambridge University Press.

Erving Goffman (1981) Forms of Talk, University of Pennsylvania Press.

Jessica Hambly (2019) 'Interactions and Identities in UK Asylum Appeals: Lawyers and Law in a Quasi-Legal Setting' in N Gill and A Good (eds) Asylum Determination in Europe: Ethnographic Perspectives, Palgrave Macmillan.

James C Hathway and Michelle Foster (2014) The Law of Refugee Status, Cambridge University Press.

Jane Herlihy, Kate Gleeson and Stuart Turner (2010) 'What Assumptions about Human Behaviour Underlie Asylum Judgments?' 22(3) International Journal of Refugee Law 351

Harry Hobbs and George Williams (2019) 'Trust and the Constitution' in M Evans et al (eds) From Turnbull to Morission: The Trust Divide: Australian Commonwealth Adminstration 2016-2019, Melbourne University Press.

Jill Hunter, Linda Pearson, Mehera San Roque and Zac Steel (2013) 'Asylum Adjudication, Mental Health and Credibility Evaluation 41(3) Federal Law Review 471.

Peter Ives (2009) 'Global English, Hegemony and Education: Lessons from Gramsci' 32(3) Higher Education Research \& Development 355.

Marco Jacquemet (2009) 'Transcribing refugees: the entextuaization of asylum seekers' hearings in a transidiomatic environment' 29(5) Text \& Talk 525.

Michael Kagan (2003) 'Is truth in the eye of the beholder? Objective credibility assessment in refugee status determination' 17 Georgetown Immigration Law Journal 367.

Bjørghild Kjelsvik (2014) “"Winning a battle, but losing the war": contested identities, narratives, and interaction in asylum interviews' 34(1) Text \& Talk 89.

Trish Luker (2013) 'Decision Making Conditioned by Radical Uncertainty: Credibility assessment at the Australia Refugee Review Tribunal' 25(3) International Journal of Refugee Law 502.

Audrey Macklin (1998) 'Truth and Consequences: Credibility Determination in the Refugee Context', The Realities of Refugee Determination on the Eve of a New Millennium: The Role of the Judiciary (3rd Conference: October 1998) (International Association of Refugee Law Judges) 134.

Katrijn Maryns (2005) 'Monolingual language ideologies and code choice in the Belgian asylum procedure' 25(3) Language \& Communication 299.

Katrijn Maryns (2006) The Asylum Speaker: Language in the Belgian Asylum Procedure, Routledge.

Emily McDonald and Maria O'Sullivan (2018) 'Protecting vulnerable refugees: Procedural fairness in the Australian fast track regime' 41(3) UNSW Law Journal 1003.

Sarah L McKinnon (2009) 'Citizenship and the Performance of Credibility: Audiencing Gender-based Asylum Seekers in U.S. Immigration Courts’29(3) Text and Performance Quarterly 205.

Jenni Millbank (2009) “"The Ring of Truth": A Case Study of Credibility Assessment in Particular Social Group Refugee Determinations’21(1) International Journal of Refugee Law 1. 
Zoe Nikolaidou, Hanna Sofia Rehnberg and Cecilia Wadensjö, 'Negotiating access with public authorities in research on asylum' Working Papers in Urban Language \& Literacies (Paper 262), https://www.academia.edu/40528658/WP262_Nikolaidou_Rehnberg_and_Wadensj\%C3\%B6_2019._ Negotiating_access_with_public_authorities_in_research_on_asylum.

Mark Nolan and Jane Goodman-Delahunty (2015) Legal Psychology in Australia, Thomson Reuters.

Gregor Noll (2005) 'Evidentiary Assessment Under the Refugee Convention: Risk, pain and the intersubjectivity of fear' in G Noll (ed) Proof, Evidentiary Assessment and Credibility in Asylum Procedures, Martinus Nijhoff.

Ingrid Piller (2001) 'Naturalization language testing and its basis in ideologies of national identity and citizenship' 5(3) International Journal of Bilingualism 259.

Ingrid Piller (2016) Linguistic Diversity and Social Justice: An Introduction to Applied Sociolinguistics, Oxford University Press.

Amy Shuman and Carol Bohmer (2014) 'Gender and cultural silences in the political asylum process' 17(8) Sexualities 939.

Amy Shuman and Carol Bohmer (2012) 'The Stigmatized Vernacular: Political asylum and the politics of visibility/recognition' 49(2) Journal of Folklore Research 199.

Laura Smith-Khan (2017a) 'Different in the Same Way?: Language, Diversity and Refugee Credibility' 29(3) International Journal of Refugee Law 389.

Laura Smith-Khan (2017b) 'Negotiating Narratives, Accessing Asylum: Evaluating language policy as multi-level practice, beliefs and management' 36(1) Multilingua 31.

Laura Smith-Khan (2017c) 'Telling Stories: Credibility and the Representation of Social Actors in Australian Asylum Appeals’ 28(5) Discourse \& Society 512.

Laura Smith-Khan (2018) Contesting Credibility in Australian Refugee Visa Decision Making and Public Discourse, PhD Thesis, Macquarie University, https://www.languageonthemove.com/wpcontent/uploads/2019/02/Smith-Khan-2018-Contesting-Credibility-Final-PhD-Thesis.pdf

Laura Smith-Khan (2019a) 'Communicative resources and credibility in public discourse on refugees' 48(3) Language in Society 403.

Laura Smith-Khan (2019b) 'Debating credibility: Refugees and rape in the media' 42(1) Australian Review of Applied Linguistics 4.

Laura Smith-Khan (2019c) 'Migration lawyers' roles in communicating credible refugee claims' Alternative Law Journal, https://doi.org/10.1177\%2F1037969X19884205.

Max Spotti (2019) “It's all about naming things right": The paradox of web truths in the Belgian asylum-seeking procedure' in G Noll (ed) Asylum Determination in Europe: Ethnographic perspectives, Palgrave Macmillan.

Carl F Stychin, "“A Stranger to its Laws": Sovereign Bodies, Global Sexualities, and Transnational Citizens' (2000) 27(4) Journal of Law and Society 601.

James A Sweeney (2009) 'Credibility, proof and refugee law' 21(4) International Journal of Refugee Law 700. 
Shonna L Trinch (2003) Latinas' narratives of domestic abuse: Discrepant versions of violence, John Benjamins.

Peter M Tiersma (1999) Legal Language, University of Chicago Press.

Rebecca Tipton (2008) 'Reflexivity and the Social Construction of Identity in Interpreter-mediated Asylum Interviews' 14(1) The Translator 1.

Susanne van der Kleij (2015) Interaction in Dutch asylum interviews: A corpus study of interpretermediated institutional discourse, LOT.

Teun A van Dijk (2008) Discourse and Power, Palgrave Macmillan.

Theo van Leeuwen (1996) 'The representation of social actors' in C R Caldas-Coulthard and M Coulthard (eds) Texts and Practices: Readings in critical discourse analysis, Taylor Francis.

Theo van Leeuwen (2008) Discourse and Practice: New Tools for Critical Analysis, Oxford University Press.

Jens Vedsted-Hansen (2005) 'The Borderline between Questions of Fact and Questions of Law' in G Noll (ed) Proof, Evidentiary Assessment and Credibility in Asylum Procedures, Martinus Nijhoff.

Jef Verschueren (2012) Ideology in Language Use: Pragmatic guidelines for empirical research, Cambridge University Press.

Anthea Vogl (2013) 'Telling Stories from Start to Finish: Exploring the Demand for Narrative in Refugee Testimony’ 22(1) Griffith Law Review 63.

Matthew Zagor (2014) 'Recognition and narrative identities: is refugee law redeemable?' in F Jenkins et al (eds) Allegiance and Identity in a Globalised World 311.

Pia Zambelli (2017) 'Hearing Differently: Knowledge-Based Approaches to Assessment of Refugee Narrative' 29(1) International Journal of Refugee Law 10.

\section{Primary Sources}

Migration Act 1958 (Cth).

UN Convention relating to the Status of Refugees (adopted 28 July 1951, entered into force 22 April 1954) 189 UNTS 137. 